\title{
Carious damage of the first permanent molar in the age group 6-9 years-old
}

\author{
Afectarea prin carie a molarului unu permanent la grupa de vârstă 6-9 ani
}

\author{
Ioana-Andreea Stanciu, Mihaela Tănase, Rodica Luca, \\ Daciana-Diana-Daniela Zmărăndache, Aneta Munteanu
}

Disciplina Pedodonţie, Facultatea de Medicină Dentară, UMF „Carol Davila“, Bucureşti, România

\begin{abstract}
Objectives. To assess the caries status of the first permanent molars (FPMs) in a group of 6-9 years-old schoolchildren from general population.

Material and method. Cross-sectional clinical study performed on a group of 268 schoolchildren (139 boys) (mean age $=7.78 \pm 1.27$ years). Clinical oral examination was performed in the classroom, in daylight, according to WHO recommendations (1997). The FPM dental status was recorded: sound, decay, treated. FPM prevalence caries index $\left(\mathrm{Ip}_{\mathrm{FPM}}\right)$, mean values of carious experience indices (DMF-T $\left.\mathrm{FPM}_{\mathrm{FP}}, \mathrm{DMF}-\mathrm{S}_{\mathrm{FPM}}, \mathrm{SiC}_{\mathrm{FPM}}\right)$ and their components were calculated and the values were assessed according to age and sex. Caries distribution according to topography, depth and treatment methods was assessed. Statistical analysis was performed with ANOVA and t-test $(p<0.05)$.

Results. $I p_{\mathrm{FPM}}=46.26 \%$; I $\mathrm{p}_{\mathrm{FPM}}$ boys $=50.35 \%, \mathrm{Ip}_{\mathrm{FPM}}$ girls $=41.86 \%(\mathrm{p}<0.05) . I \mathrm{I}_{\mathrm{FPM}}=29.16 \%$ - at 6 years, $33.82 \%$ - at 7 years, $50 \%$ - at 8 years, $61.7 \%$ - at 9 years. DMF-T dental status: $69.4 \%$ - caries-free, $4.58 \%$ - non-cavitated caries, $20.51 \%$ - uncomplicated cavitated caries, $0.09 \%$ - complicated caries and $5.37 \%$ - filled. The most frequent lesions were uncomplicated occlusal caries $-88.88 \%$. Conclusions. Approximately half of the examined children had at least one FPM decayed on at least one surface. Regular dental check-ups are required shortly after the FPM eruption, which would allow the application of preventive methods or the detections of lesions at an early stage and the use of minimally invasive treatment methods.
\end{abstract}

Keywords: FPM, caries, schoolchildren

\begin{abstract}
REZUMAT
Obiective. Evaluarea afectării prin carie a molarului unu permanent (M1p) la un grup de şcolari în vârstă de 6-9 ani din populaţia generală.

Material şi metodă. Studiu clinic transversal realizat pe un lot de 268 de elevi (139 băieţi) (vârsta medie = $7,78 \pm 1,27$ ani). Examinarea clinică a fost efectuată în sala de clasă, la lumină naturală, conform recomandărilor OMS (1997). S-a înregistrat statusul odontal al M1p: indemn, cariat, tratat. S-au calculat: indicele de prevalenţă a cariei la nivelul M1p $\left(\mathrm{Ip}_{\mathrm{M1}}\right)$, valorile medii totale şi pe componente ale indicilor de experienţă carioasă (DMF-T ${ }_{M 1 p}, D_{M F}-S_{M 1 p}$, $\mathrm{SiC}_{\mathrm{M} 1 \mathrm{p}}$ ) şi s-au evaluat valorile lor în funcţie de vârstă şi sex. S-a analizat distribuţia proceselor carioase în funcţ̧ie de topografie, profunzime şi metodele de tratament aplicate. Analiza statistică s-a realizat cu programul SPSS 18.0, folosind testele ANOVA şi t-test $(p<0,05)$.

Rezultate. $I p_{M 1 p}=46,26 \%$; $I p_{M 1 p}$ băieţi $=50,35 \%$, I $p_{M 1 p}$ fete $=41,86 \%(p<0,05)$. I $p_{M 1 p}=29,16 \%-l a$ ani, 33,82\% - la 7 ani, $50 \%$ - la 8 ani, $61,7 \%$ - la 9 ani. DMF-T ${ }_{M 1 \mathrm{p}}=0,93 ;$ DMF-S $_{\mathrm{M} 1 \mathrm{p}}=1,1 ; \mathrm{SIC}_{\mathrm{M} 1 \mathrm{p}}=2,43$. Statusul odontal al M1p: $69,4 \%$ - indemni de carie, $4,58 \%$ - cu marmorații, $20,51 \%$ - carii simple, $0,09 \%$ - carii complicate şi 5,37\% - obturaţi. Cel mai frecvent întâlnite au fost cariile simple ocluzale $-88,88 \%$.

Concluzii. Aproximativ jumătate dintre copiii examinaţi au prezentat cel puţin un $\mathrm{M} 1 \mathrm{p}$ cariat pe cel puţin o suprafaţă. Se impune necesitatea controalelor stomatologice regulate cât mai aproape de erupţia M1p, ceea ce ar permite aplicarea metodelor preventive sau surprinderea leziunilor într-un stadiu precoce şi folosirea metodelor de tratament minimum invazive.
\end{abstract}

Cuvinte cheie: M1p, carie, elevi

\section{INTRODUCERE}

Molarul unu permanent (M1p) ocupă o poziţie specială în cadrul aparatului dento-maxilar, fiind primul dinte permanent care erupe atât la maxilar, cât și la mandibulă, ghidând erupția dinților permanenți, având un rol fundamental în stabilirea ocluziei, distribuind uniform forțele și fiind predictor al cariei pentru întreaga dentiție permanentă [1]. 
Patologia carioasă a acestui dinte permanent este variată ca urmare a vulnerabilității sale crescute. Această susceptibilitate apare din cauza erupției sale timpurii, a morfologiei sale ocluzale accidentate cu șanțuri și fosete adânci, a proximității cu molarul secund temporar cariat și a smalțului, care este incomplet mineralizat la momentul erupției [1]. Astfel, în absența unor măsuri preventive aplicate timpuriu, leziunile carioase se pot grefa foarte rapid după erupția pe arcadă, numeroase studii raportând valori destul de ridicate ale prevalenței cariei pe M1p încă de la vârsta de 7 ani: de la 2,89\% în Albania (Canga și colab., 2018) [2] la 8,7\% în China (Wang și colab., 2012) [3], până la 56,76\% în Iran (Yaghooti și colab., 2009-2010) [4] și chiar $80,7 \%$ în Polonia (Olczak-Kowalczyk și colab., 2017) [5].

În acest context, obiectivul studiului a fost evaluarea afectării prin carie a M1p la un grup de școlari în vârstă de 6-9 ani din populația generală.

\section{MATERIAL ŞI METODĂ}

Lotul a fost alcătuit din 268 de copii (139 băieți) cu vârste cuprinse între 6 și 9 ani (vârsta medie = 7,78 $\pm 1,27$ ani), elevi ai Școlii generale nr. 196 din București (fig. 1).

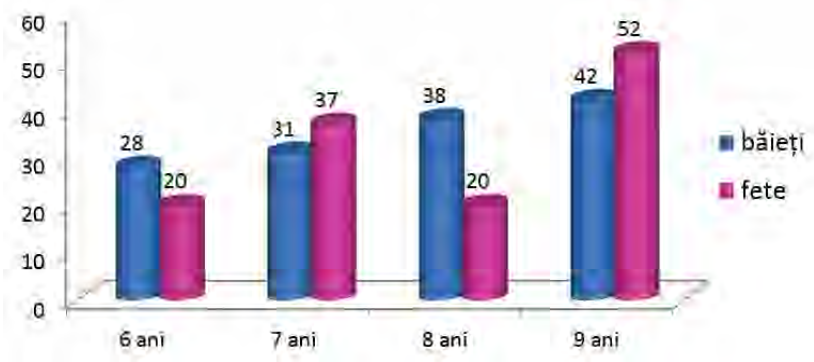

FIGURA 1. Distribuția pe vârstă şi sexe a lotului de studiu ( $n=268$ copii)

Criteriile de includere în studiu au fost: cel puțin un M1p erupt în cavitatea bucală la copii fără afecțiuni generale, la care s-a obținut acordul semnat al părinţilor.

Cercetarea a constat într-un studiu clinic transversal realizat prin examinarea copiilor în sălile de clasă, la lumină naturală, fără o sursă de lumină suplimentară, folosind instrumentar de consultație obișnuit (oglindă și sondă dentară), conform recomandărilor OMS (1997) [6]. Dinții nu au fost uscaţi înaintea examinării, dar depozitele moi au fost în- depărtate cu o compresă sterilă. S-a înregistrat statusul odontal al M1p: indemni, cariați, tratați. Au fost considerate drept carii leziunile cavitare și necavitare la care s-a observat prin transparență prezența dentinei alterate.

Datele culese au fost îndosariate electronic întro bază de date și prelucrate cu ajutorul programului SPSS 18.0. S-au calculat indicele de prevalență a cariei la nivelul M1p ( $\left.\mathrm{Ip}_{\mathrm{M} 1 \mathrm{p}}\right)$, frecvența copiilor indemni la carie, valorile medii totale și pe componente ale indicilor de experiență carioasă (DMF$\mathrm{T}_{\mathrm{Mlp}}, \mathrm{DMF}-\mathrm{S}_{\mathrm{Mlp}}, \mathrm{SiC}_{\mathrm{Mlp}}$ ) și s-au evaluat aceste valori în funcție de vârstă și sex. De asemenea, s-a analizat distributia proceselor carioase în functie de topografie, profunzime și tratament. Analiza statistică s-a realizat cu testele ANOVA și t-test pentru un nivel de semnificație statistică ales de $p<0,05$.

\section{REZULTATE}

\section{Indicele de prevalență a cariei pe $M 1 p\left(\mathrm{Ip}_{\mathrm{M} 1 \mathrm{p}}\right)$}

Din analiza datelor, a rezultat că $\mathrm{Ip}_{\mathrm{M} 1 \mathrm{p}}$ la întregul lot studiat a fost de $46,26 \%$. Raportat pe sexe, $\mathrm{Ip}_{\mathrm{Mlp}}$ la băieți a fost de 50,35\% și Ip $\mathrm{M}_{\mathrm{M} 1 \mathrm{p}}$ la fete de 41,86\%, diferența fiind semnificativă statistic $(\mathrm{p}<0,05)$. Valorile $\mathrm{Ip}_{\mathrm{M} 1 \mathrm{p}}$ au fost crescătoare cu vârsta: de la $29,16 \%$ la 6 ani, $33,82 \%$ - la 7 ani, $50 \%$ - la 8 ani până la $61,7 \%$ - la 9 ani. Distribuția valorilor $\mathrm{Ip}_{\mathrm{M} 1 \mathrm{p}}$ pe grupe de vârstă și sexe este reprezentată în figura 2.

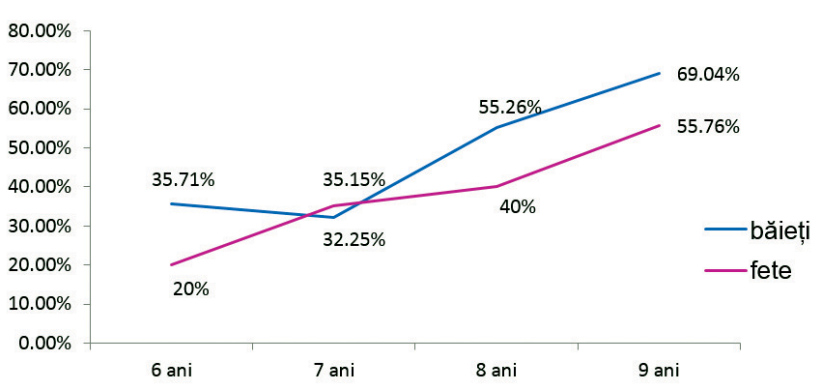

FIGURA 2. Distribuția pe grupe de vârstă şi sexe a $I p_{M 1 p}$

Dintre cei 268 de elevi examinați, 53,73\% (144) au avut toți cei patru M1p indemni de carie, în timp ce $6,34 \%$ au prezentat carii pe toți cei patru M1p.

\section{Experiența carioasă la nivelul $M 1 p$}

Pentru întregul lot, valorile indicilor de experiență carioasă au fost: $\mathrm{DMF}_{\mathrm{Mlp}}=0,93$ și DMF-S $\mathrm{S}_{\mathrm{Mlp}}=1,1$, variația cu vârsta fiind 
TABEL 1. Distribuția $D M F-T / S_{M 1 p}$ pe grupe de vârstă şi sexe

\begin{tabular}{|c|c|c|c|c|c|c|c|c|c|c|c|c|}
\hline & \multicolumn{3}{|c|}{6 ani } & \multicolumn{3}{|c|}{7 ani } & \multicolumn{3}{|c|}{8 ani } & \multicolumn{3}{|c|}{9 ani } \\
\hline & B & $\mathbf{F}$ & total & B & $F$ & total & B & $F$ & total & B & $\mathbf{F}$ & total \\
\hline DMF-T & 0,64 & 0,25 & 0,46 & 0,96 & 0,4 & 0,66 & 0,97 & 0,8 & 0,91 & 1,47 & 1,3 & 1,38 \\
\hline DMF-S & 0,78 & 0,25 & 0,56 & 1,02 & 0,51 & 0,77 & 1,07 & 1 & 1,05 & 1,85 & 1,46 & 1,64 \\
\hline
\end{tabular}

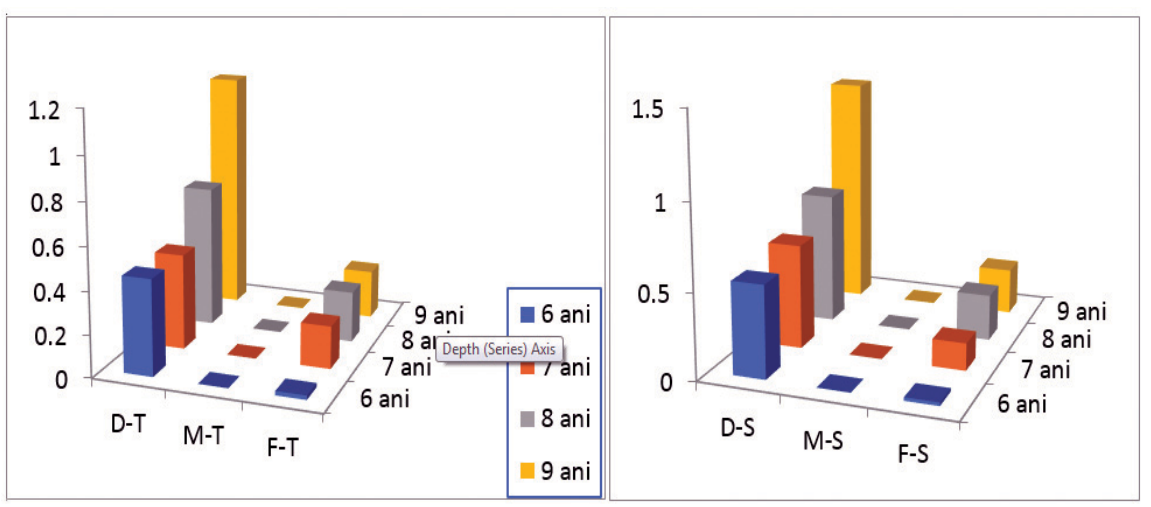

FIGURA 3. Analiza indicelui DMF-T/S ${ }_{M 1 p}$ în funcție de componente

proporțională. Raportat la sex s-au calculat următoarele valori: la băieți - DMF- $\mathrm{T}_{\mathrm{M} 1 \mathrm{p}}=0,95$ și DMF$\mathrm{S}_{\mathrm{Mlp}}=1,13$; la fete $-\mathrm{DMF}_{\mathrm{Mlp}}=0,92$ și DMF-S $\mathrm{S}_{\mathrm{Mlp}}$ $=1,06$, diferentele fiind nesemnificative statistic $(p>0,05)$. Valorile pe grupe de vârstă și sex sunt prezentate în tabelul 1.

Analiza indicilor $\mathrm{DMF}-\mathrm{T} / \mathrm{S}_{\mathrm{M} 1 \mathrm{p}}$ în funcție de componente (D-T/S, M-T/S, F-T/S) arată că a predominat componenta $\mathrm{D}$, nefiind înregistrat niciun M1p extras (fig. 3).

Indicele $\mathrm{SiC}_{\mathrm{Mlp}}$ (indicele semnificativ de carie), calculat ca media valorilor DMF-T de la $1 / 3$ dintre copiii cu cel mai mare DMF-T ${ }_{\text {Mlp }}$, a avut valoarea de 2,43 .

\section{Afectarea prin carie a M1p}

Cei 268 de copii luaţi în studiu au avut în total 1.004 M1p erupți pe arcadă. Dintre aceștia, 69,4\% (697) erau indemni de carie, 4,58\% (46) prezentau marmorații, 20,51\% (206) - carii simple, 0,09\% (1) - carii complicate și 5,37\% (54) - obturații. Distribuția afectării prin carie a M1p în funcție de grupele de vârstă este dată în tabelul 2.
Cel mai frecvent întâlnite au fost cariile localizate pe suprafața ocluzală, urmate de cele localizate pe suprafețele netede, mezial și vestibular la colet (tabelul 3).

TABEL 3. Distribuția M1p cariați în funcție de vârstă şi topografie

\begin{tabular}{|c|c|c|c|c|c|}
\hline \multirow{2}{*}{$\begin{array}{c}\text { Vârsta } \\
\text { (ani) }\end{array}$} & \multirow{2}{*}{$\begin{array}{c}\text { Total M1p } \\
\text { erupți }\end{array}$} & \multicolumn{2}{|c|}{ Carii ocluzale } & \multicolumn{2}{|c|}{$\begin{array}{c}\text { Carii pe suprafețe } \\
\text { netede }\end{array}$} \\
\cline { 3 - 6 } & & $\mathbf{n}$ & $\mathbf{\%}$ & $\mathbf{n}$ & $\mathbf{\%}$ \\
\hline 6 & 146 & 24 & 16,43 & 2 & 1,36 \\
\hline 7 & 255 & 30 & 11,76 & 3 & 1,17 \\
\hline 8 & 227 & 39 & 17,18 & 4 & 1,76 \\
\hline 9 & 376 & 92 & 24,46 & 13 & 3,45 \\
\hline
\end{tabular}

\section{DISCUṬII}

Particularitățile morfofuncționale, precum și contextul general în care M1p erupe și devine funcțional creează toate condițiile pentru grefarea precoce a leziunilor carioase la acest nivel. M1p este, astfel, cel mai afectat dinte chiar și la copiii cu carioactivitate redusă.

În studiul prezent, indicele de prevalență a cariei la nivelul M1p a fost de 46,26\%, valorile crescând

TABEL 2. Afectarea prin carie a M1p în funcție de grupa de vârstă

\begin{tabular}{|c|c|c|c|c|c|c|c|c|c|c|}
\hline \multirow{2}{*}{$\begin{array}{c}\text { Vârsta } \\
\text { (ani) }\end{array}$} & \multicolumn{2}{|c|}{ Indemni } & \multicolumn{2}{c|}{ Marmorații } & \multicolumn{2}{c|}{ Carie simplă } & \multicolumn{2}{c|}{ Carie complicată } & \multicolumn{2}{c|}{ Obturații } \\
\cline { 2 - 12 } & $\mathbf{n}$ & $\%$ & $\mathbf{n}$ & $\mathbf{\%}$ & $\mathbf{n}$ & $\mathbf{\%}$ & $\mathbf{n}$ & $\mathbf{\%}$ & $\mathbf{n}$ & $\%$ \\
\hline 6 & 114 & 78,02 & 5 & 3,42 & 26 & 17,8 & 0 & 0 & 1 & 0,68 \\
\hline 7 & 195 & 76,47 & 12 & 4,7 & 33 & 12,94 & 0 & 0 & 15 & 5,88 \\
\hline 8 & 164 & 72,24 & 7 & 3,08 & 43 & 18,94 & 0 & 0 & 13 & 5,73 \\
\hline 9 & 224 & 59,57 & 22 & 5,85 & 104 & 27,65 & 1 & 0,26 & 25 & 6,64 \\
\hline
\end{tabular}


cu vârsta, de la 29,10\% la 6 ani la 61,7\% la 9 ani. Rezultatele sunt comparabile cu cele raportate în literatura de specialitate.

TABEL 4. Indicele de prevalență al cariei la nivelul M1p la 6-9 ani - date comparative

\begin{tabular}{|l|l|c|c|c|}
\hline Autori/An studiu & Țara/Oraș & Lot & $\begin{array}{c}\text { Vârstă } \\
\text { (ani) }\end{array}$ & $\begin{array}{c}\mathbf{I p}_{\text {M1p }} \\
(\mathbf{\%})\end{array}$ \\
\hline $\begin{array}{l}\text { Șerban și colab., } \\
\text { 2009 [7] }\end{array}$ & România/Iași & 280 & $6-8$ & 34,8 \\
\hline $\begin{array}{l}\text { Xue și colabl., } \\
2015 \text { [8] }\end{array}$ & China/Tangshan & 1794 & $7-9$ & 47,49 \\
\hline $\begin{array}{l}\text { Dukic și colab., } \\
2011[9]\end{array}$ & Croația/Zagreb & 734 & $7-10$ & 48,1 \\
\hline $\begin{array}{l}\text { El Batawi și colab., } \\
2017 \text { [10] }\end{array}$ & $\begin{array}{l}\text { Emiratele Arabe } \\
\text { Unite/Sharjah }\end{array}$ & 348 & $7-9$ & 67 \\
\hline $\begin{array}{l}\text { Studiul prezent, } \\
\mathbf{2 0 1 5}\end{array}$ & $\begin{array}{l}\text { România/ } \\
\text { București }\end{array}$ & $\mathbf{2 6 8}$ & $\mathbf{6 - 9}$ & $\mathbf{4 6 , 2 6}$ \\
\hline
\end{tabular}

Valorile indicelui de prevalență au fost semnificativ statistic mai mari la băieți $(50,35 \%)$ decât la fete $(41,86 \%)$. Acest rezultat este în contradicție cu datele raportate în literatura de specialitate. Mai multe studii susțin că fetele au o frecvență mai mare a cariei pe M1p, deoarece au o erupție a M1p mai timpurie, au o rată de excreție salivară mai mică, IgA în cantitate mai mică decât băieții și dietă cu mai multe gustări dulci între mese [11]. Astfel, Riziwaguli și colab. [12] au obținut o prevalență mai crescută a leziunilor carioase la fete (30\%) față de băieți (22,98\%). De asemenea, Leroy și colab. (2005), într-un studiu longitudinal efectuat timp de 6 ani pe un lot de 4.468 de copii belgieni, au găsit că fetele au avut o incidență mai mare decât băieții în formarea cariei pe M1p [13]. Și Beltran și colab. (2006) susțin că fetele au o afectare mai mare prin carie decât băieții [14]. În schimb, Saravanan și colab. (2007) [15], Peedikayil și colab. (2010-2011) [16] și Gomez Capote și colab. (2015) [17] nu au găsit diferențe semnificative între sexe.

Referitor la indicii de experienţă carioasă DMF$\mathrm{T} / \mathrm{S}_{\mathrm{M} 1 \mathrm{p}}$, în studiul prezent s-a constatat că valorile acestora au fost mici $-0,93$, respectiv 1,1 , ceea ce înseamnă că fiecare copil a avut în medie un M1p cu leziuni carioase sau obturații pe o singură suprafață. Valorile sunt comparabile cu rezultatele altor studii similare (tabel 5).

Analiza indicilor pe componente a arătat că la lotul studiat au predominat componentele D-T/S $\mathrm{S}_{\mathrm{Mlp}}$ (carie netratată pe dinte/suprafaţă), atât pe grupe de vârstă, cât și pe sexe, componentele F-T/S $\mathrm{S}_{\mathrm{Mlp}}$ (obturație pe dinte/suprafață) având valori mici: 0,19, respectiv 0,2. Dintre cei $207 \mathrm{M} 1 \mathrm{p}$ afectați de carie, doar 5,37\% erau obturați. Toate aceste date arată nivelul scăzut de educație sanitară, dar și adresabilitatea redusă la medic. Xue și colab. (2015) [8] au găsit un procent de 2,35\% M1p obturați la un lot de 1.794 de copii de 7-9 ani din Tangshan, China, în timp ce, în studiul realizat în Islamabad, Pakistan, pe 543 copii de 6-9 ani, Abdulahh și colab. (2005) nu au găsit niciun M1p obturat [20]. Componenta $\mathrm{D}-\mathrm{T}_{\mathrm{Mlp}}$ a fost găsită și de Peedykail și colab. (2010-2011) ca fiind predominantă într-un procent de $90,01 \%$ ca urmare a lipsei de tratament, acesta fiind considerat de autori un motiv de îngrijorare [16]. Totuși, există și un aspect pozitiv obținut în urma analizei DMF-T/ $\mathrm{S}_{\mathrm{Mlp}}$ : componentele $\mathrm{M}-\mathrm{T} / \mathrm{S}_{\mathrm{M} 1 \mathrm{p}}$ (absent prin carie/dinte/ suprafață) au fost 0 .

Din punctul de vedere al topografiei cariilor, s-a constat că la toate grupele de vârstă au predominat cariile ocluzale, cariile de pe suprafețele netede fiind întâlnite mai frecvent spre vârsta de 9 ani și în special pe fața mezială, ca urmare a creșterii punctelor de contact cu molarii 2 temporari. Aceste rezultate se datorează vulnerabilității crescute a suprafeței ocluzale, dar și inexistenței unor programe de profilaxie la nivel local și național. Rezultate asemănătoare au obținut și alți autori. Astfel, Ramazani și colab. (2013), într-un studiu efectuat pe 85 de copii din Zahedan, Iran, au găsit că $21,8 \%$ dintre suprafețele ocluzale ale $193 \mathrm{M} 1 \mathrm{p}$ semierupţi aveau deja leziuni carioase grefate [21]. Wang și colab. au constatat că toate cariile în dentină depistate la un lot de 1.043 de copii de 7-8 ani din Wuhan, China, erau localizate pe suprafața ocluzală a

TABEL 5. Indici de experiență carioasă - date comparative

\begin{tabular}{|l|l|c|c|c|c|}
\hline Autori (an) & Țara/ Oraș & Lot & Vârstă (ani) $^{\text {DMF-T }_{\text {M1p }}}$ & DMF-S $_{\text {M1p }}$ \\
\hline Bercescu și colab., 2012 [18] & România/Tg. Mureș & 385 & $6-8$ & 0,87 & - \\
\hline Stanciu și colab., 2011 [19] & România/Slatina & 178 & $6-8$ & 0,88 & 1,07 \\
\hline Wang și colab., 2012 [3] & China/Hubei & 1.043 & $7-8$ & 0,11 & 0,14 \\
\hline Xue și colab., 2015 [8] & China/Tangshan & 1.794 & $7-9$ & 1,3 & 1,96 \\
\hline Studiul prezent, 2015 & România/București & $\mathbf{2 6 8}$ & $\mathbf{6 - 9}$ & $\mathbf{0 , 9 3}$ & $\mathbf{1 , 1}$ \\
\hline
\end{tabular}


M1p [3]. Batchelor și colab. (2004), într-un studiu longitudinal efectuat pe 20.000 de copii de 5-16 ani din SUA, au găsit, de asemenea, că cele mai susceptibile suprafețe la atacul carios au fost fețele ocluzale și fosetele vestibulare ale M1p [22]. McDonald subliniază, de asemenea, frecvența mare a cariei ocluzale pe M1p la toate grupele de vârstă [23].

\section{CONCLUZII}

Aproximativ jumătate dintre copiii examinați au prezentat cel puțin un M1p cariat, iar 6,34\% au prezentat carii pe toți cei patru M1p. Cariile simple ocluzale au constituit patologia cel mai frecvent întâlnită. Se impune necesitatea realizării unor programe profilactice locale și naționale atât pentru a putea aplica sigilări la cât mai mulți M1p cât mai rapid după erupție, cât și pentru a crea obligativitatea controalelor stomatologice regulate astfel încât să se surprindă leziunile într-un stadiu incipient, metodele de tratament necesare fiind astfel minimum invazive.

\section{Menţiune}

Autorii au contribuit în mod egal la prezentul articol, de aceea toți sunt considerați autori principali.

Conflict of interest: none declared Financial support: none declared

\section{BIBLIOGRAFIE}

1. Zarnea L. Pedodonție. București: Ed. Didactică și Pedagogică, 1993:196-8.

2. Canga M, Malagnino AV. The first permanent molar most affected by dental caries - a longitudinal study. Int J Dent Med. 2018;4(2):36-41.

3. Wang JD, Chen X, Frencken J et al. Dental caries and first permanent molar pit and fissure morphology in 7 to 8-years-old children in Wuhan, China. Int J Oral Sci. 2012;4:157-60.

4. Yaghooti Khorasani MM, Irannezhad M. The prevalence of caries on the first permanent molars among students of 7 and 12 years of age in Rafsanjan, Iran in 2009-2010. JOHE. 2017;6(1):25-31.

5. Olczak-Kowalczyk D, Gozdowski D, Kaczmarek V. Dental caries in permanent dentition in children aged 5 and 17 in Poland and its association with dental caries in primary dentition. Borgis-Nowa Stomato. 2017;3:129-41.

6. World Health Organisation. Oral health survey: basic method, 1997;3:21-46.

7. Șerban V, Maxim A, Bălan A. Study on the caries of the first permanent molar in children aged between 6 and 13 years. $J$ Rom Med Dent. 2009;13:138-41.

8. Xue Y, Lin W, Jie L, Qing D. Caries status of the first permanent molar among 7-to 9-year-old children in Tangshan city and their correlation. Hua Xi Kou Qiang Yi Xue Za Zhi. 2015;33:54-7.

9. Dukic W, Delija B, Lulic Dukic O. Caries prevalence among schoolchildren in Zagreb, Croatia. Croat Med J. 2011;52:665-71.

10. Batawi HE, Fakhruddin KS. Patterns of dental caries among school children assessed using Caries Assessment Spectrum and Treatment tool. Eur J Dent. 2017;11(2):168-173.

11. Ali NS, Khan $M$ et al. Prevalence of dental caries in the first permanent molars in children between 8-12 years. J Ala Dent Assoc. 2013;22(13):119-23.

12. Riziwaguli A, Asiya $Y$, Liu $Y$ et al. Caries prevalence of the first permanent molar among 7-9 years old Uygur children in Urumqi, Xinjiang Autonomous Region. Shangai Kou Qiang Yi Xue. 2013;22(5):559-61.
13. Leroy R, Bogaerts K, Lesaffre $E$ et al. Multivariate survival analysis for the identification of factors associated with cavity formation in permanent first molars. Eur J Oral Sci. 2005;113(2):145-52.

14. Beltran-Valladares PR, Cocom-Tun $\mathrm{H}$, Casanova-Rosado JF et al. Caries prevalence and some associated factors in 6-9-year-old schoolchildren in Campeche, Mexico. Rev Biomed. 2006;17:25-33.

15. Saravannan S, Kalyiani V, Vijayarani MP et al. Caries prevalence and treatment needs of rural schoolchildren in Chidambaram Taluk, Tamil Nadu, South India. Ind J Dent Res. 2008;19:186-90.

16. Peedikayil FC, Kottayi S, Kenchamba V et al. Dental caries prevalence and treatment needs of school going children in Kannur District, Kerala. SRM J Res Dent Sci. 2013;4:51-3.

17. Gomez Capote I, Hernandez Roca CV, Montano VL et al. Dental caries in the first permanent molars in schoolchildren. Rev Med Electron. 2015;37(3):207-17.

18. Bercescu L, Păcurar M, Petcu B. Clinical-statistical study regarding the decay frequency of the first permanent molars. Rom J Oral Rehab. 2012;4(4):22-6.

19. Stanciu IA, Luca R, Munteanu A, Farcașiu C, Badea VA. Studiu epidemiologic privind caria primului molar permanent la elevii din populația generală. Rev Rom Med Dent. 2011;14(3):186-202.

20. Abdulahh S, Qazi HS, Maxood A. Dental caries status in 6-9 years old children. Pak Oral Dent J. 2005;28(1):5-10.

21. Ramazani N, Ahmadi R et al. Prevalence of semi-erupted first permanent molar occlusal caries and evaluation related clinical factors in children. Zahedan J Res Med Sci. 2013;15(1):e93151.

22. Batchelor PA, Sheiham A. Grouping of tooth surfaces by susceptibility to caries: A study in 15-16 year-old children. BMC Oral Health. 2004;4(2): 50-6.

23. McDonald RE, Sheiham A. The distribution of caries on different tooth surfaces at varying levels of caries - a compilation of data from 18 previous studies. Community Dent Health. 1992;9(1):39-48. 